\title{
Doação de órgãos: dilemas dos familiares na doação de órgãos
}

\author{
Organ donation: family dilemmas in organ donation
}

\section{Donación de órganos: dilemas familiares en la donación de órganos}

\begin{abstract}
Martha Alves de Moraes Amazonas ${ }^{1 *}$, Jéssica Silva dos Santos ${ }^{1}$, Jhones Coelho Araujo ${ }^{1}$, Antônia Thalya Alves da Conceição Souza ${ }^{1}$, Matheus Branches Coelho ${ }^{1}$, João Paulo Silva dos Santos ${ }^{1}$, Eliton José Franco de Souza' ${ }^{1}$, Warlem Gomes Costa Silva ${ }^{1}$, Nayara Maria Oliveira Castilho' ${ }^{1}$, Silvana Nunes Figueiredo'.
\end{abstract}

\section{RESUMO}

Objetivo: Investigar a hesitação que levam os familiares em negar-se em consentir a doação de órgãos de seu ente querido e descrever os fatores envolvidos no processo de doação de órgãos e tecidos. Salientando a importância do papel da enfermagem no processamento da doação de órgãos. Métodos: Trata-se de um estudo descritivo exploratório onde se optou por métodos de Revisão Integrativa de Literatura (RIL). Resultados: Entre os fatores relacionados à recusa familiar para a doação, estão: desconhecimento sobre morte encefálica, crenças e religiões, a relação do profissional com a família, o desconhecimento da vontade do falecido, ainda em vida, de querer ser doador, conflitos familiares e questões emocionais. Considerações finais: Conclui-se que com a perda do ente querido, os familiares vivem um luto doloroso. Desta forma, o profissional devidamente capacitado poderá ajudar a família no ato de permitir a doação, esclarecendo toda e qualquer dúvida que possa surgir durante o processo.

Palavras-chave: Família, Obtenção de órgãos e tecidos, Enfermagem, Educação continuada.

\begin{abstract}
Objective: Investigate the hesitation that lead family members to refuse to consent to the donation of organs from their loved one and describe the factors involved in the process of organ and tissue donation. Emphasizing the importance of the role of nursing in the processing of organ donation. Methods: This is an exploratory descriptive study in which the method of Integrative Literature Review (RIL) was chosen. Results: Among the factors related to family refusal to donate are: ignorance about brain death, beliefs, and religions, the professional's relationship with the family, ignorance of the deceased's will, still alive, to want to be a donor, family conflicts and emotional issues. Final considerations: It is concluded that with the loss of the loved one, the family members experience a painful mourning. In this way, the duly trained professional will be able to help the family in the act of allowing the donation, clarifying any and all doubts that may arise during the process.
\end{abstract}

Keywords: Family, Obtainment of organs and tissues, Brain death, Continuing education, Nursing.

\section{RESUMEN}

Objetivo: Investigar las dudas que tienen los familiares al negarse a dar su consentimiento para la donación de los órganos de sus seres queridos y describir los factores involucrados en el proceso de donación de órganos y tejidos. Destacando la importancia del papel de la enfermería en el proceso de la donación de órganos. Métodos: Se trata de un estudio descriptivo exploratorio en el que se eligieron los métodos de Revisión Integrativa de Literatura (RIL). Resultados: Entre los factores relacionados con la negativa familiar a donar se encuentran: desconocimiento sobre muerte cerebral, creencias y religiones, relación del profesional con la familia, desconocimiento de la voluntad del fallecido, aún con vida, querer ser donante, conflictos familiares y problemas emocionales. Consideraciones finales: Se concluye que con la pérdida del ser querido, los familiares experimentan un doloroso duelo. De esta forma, el profesional debidamente capacitado podrá ayudar a la familia en el acto de permitir la donación, aclarando todas y cada una de las dudas que puedan surgir durante el proceso.

Palabras clave: Familia, Obtención de órganos y tejidos, Enfermería, Educación continua.

${ }^{1}$ Centro Universitário de Manaus (FAMETRO), Manaus - AM. *E-mail: marthaalvesm@gmail.com

SUBMETIDO EM: 11/2020

ACEITO EM: 11/2020

PUBLICADO EM: 1/2021 


\section{INTRODUÇÃO}

O primeiro transplante realizado no Brasil aconteceu no ano de 1964, na cidade do Rio de Janeiro. O Transplante renal foi um sucesso e desde então os avanços tecnológicos não acabaram. Com isso foi possível proporcionar ao homem uma esperança de sobrevida maior que a estimada frente ao seu presente diagnóstico clínico (DALBEM GG e CAREGNATO RCA, 2010).

O Transplante de órgãos é assegurado por Lei, conforme prescrito no art. $4^{\circ}$ Lei 10.211 de 2001, de 23 de março, o qual permite a remoção de partes do corpo para a transferência de órgãos (BRASIL, 2001). Hoje, a parentela que assentir com a concessão, considerando o grau de parentesco com o doador, ou seja, só poderá assinar a autorização o cônjuge ou parentes até o segundo grau, sendo maior de idade.

A falência cerebral é uma disposição clínica que favorece para a transferência de tecidos e órgãos, conforme o Art. $1^{\circ}$ da Resolução Conselho Federal de Medicina (CFM) 1.480/97. Visto que desde 0 abrimento do registro de morte cefálica até a confirmação do diagnóstico a CIHDOTT que é Comissão Intra Hospitalar de Doação de Órgãos e Tecidos para Transplantes, conduz a parentela, pretendendo acolher e tirar as duvida que possam surgir nos familiares do paciente sobre o diagnóstico e sobre uma possível doação (PASSONI R et al, 2017).

Depois de feito a validação da falência cerebral o comitê da CIHDOTT é acionado e a própria equipe do Centro de Transplante é responsável por falar com a família e pelo preenchimento de um formulário específico. Neste formulário constam dados do potencial doador como, idade, sexo, estado civil e a causa que levou o paciente a óbito, que pode ser morte encefálica ou uma parada cardíaca. Constará o nome do profissional e a data que foi efetuada a conversa com a parentada de primeiro grau e se for detectado desacordo na captação, é necessário estar explícito a causa (DALBEM GG e CAREGNATO RCA, 2010).

Dada a informação para a família sobre a morte cerebral do seu ente querido, inicia um caminho permeado de dilemas, anseios e dúvidas, pois a recusa por parte da parentela do futuro doador, no momento atual, consiste em ser um obstáculo para reduzir o quantitativo de pessoas em filas de espera, no Brasil e torná-lo um país referência em Transplantes. Mesmo com tanta tecnologia e avanços na ciência a falta de conhecimento acerca do assunto contribui para a recusa da família. Há outros fatores que também implicam como o pouco ou quase nenhum saber referente à falência cerebral e o concessor não ter manifestado, durante sua vivência, a vontade de querer doar, a questão religiosa também é um fator que implica na decisão, apesar de certas religiões apoiarem a doação como forma de "amor ao próximo", os familiares acreditam que seu ente querido possa sair do quadro de morte encefálica. Outro ponto abordado em pesquisas é a cordialidade entre a equipe multiprofissional com a família durante todo o processo de internação até o diagnóstico (CINQUE VM e BIANCHI ERF, 2010).

As ações educacionais são essenciais para a explanação sobre a concessão de órgãos. A importância de divulgar esse tema é gerar no âmbito familiar discussões acerca do assunto, considerando que um dos obstáculos para a efetivação de transplantes de órgãos é o desconhecimento da família, sobre o desejo de serem doadores. Os meios de comunicação são primordiais para que isso aconteça, pois, a informação é uma ferramenta que alcança cada indivíduo seja por televisão, rádio, celular, revistas e jornais (MORAIS TR e MORAIS MR, 2012). Para que seja consentida a transferência de órgãos, é essencial que a parentela conceda. A Lei no 9.434, de 1997 de 4 de fevereiro, compõe a legitimidade sobre a extração de partes do corpo a fins de transferência e tratamento, desde que seja de livre escolha e autorização pelo familiar de primeiro grau (filho, pai, mãe e cônjuge) (SILVA VS, et al., 2020).

O estudo refere-se a identificar por meio de uma revisão os dilemas vivenciados pela parentela no decorrer do processo em consentir em doar após a morte. De modo que o atual estudo se questiona a razão que gera a resistência da parentela em permitir a concessão dos tecidos e órgãos.

\section{MÉTODOS}

O estudo refere-se exploratório descritivo onde se optou por métodos de Revisão Integrativa de Literatura (RIL). Com o objetivo de identificar a hesitação no ato em doar os tecidos, possibilitando uma compreensão 
acerca da dos fatores que proporcionam o desacordo entre os parentes. A pesquisa por artigos científicos foi desempenhada em abril a agosto de 2019, dispondo-se das bibliotecas virtuais Biblioteca Científica Eletrônica Online (SCIELO) e Literatura Latino Americana e do Caribe em Ciência da Saúde (LILACS). Por intermédio dos descritores "Família", "Obtenção de órgãos e tecidos", "Enfermagem" e "Educação continuada".

No que tange aos critérios de elegibilidade: artigos publicados nos últimos 10 anos, no período de Janeiro de 2010 à Dezembro de 2020, nos idiomas inglês e português, completos e disponíveis de forma grátis. Anulando artigos em forma de resumo, monografias, dissertação de mestrado. Para alcançar o objetivo, foi definida a seguinte pergunta norteadora "qual o dilema em permitir a doação de órgãos por parte dos familiares."

\section{RESULTADOS E DISCUSSÃO}

Após a busca dos artigos através das bases de dados científicas na Biblioteca Virtual em Saúde, SCIELO e LILACS, dos 109 artigos encontrados, após esmiuçar, conforme os critérios de elegibilidade e de relevância para o presente estudo, utilizando os intervalos de ano de publicação dos últimos 10 anos, foram selecionados 29 artigos no total, conforme o Fluxograma da Figura 1 apresentou os seguintes resultados:

Figura 1 - Fluxograma representativos dos artigos.
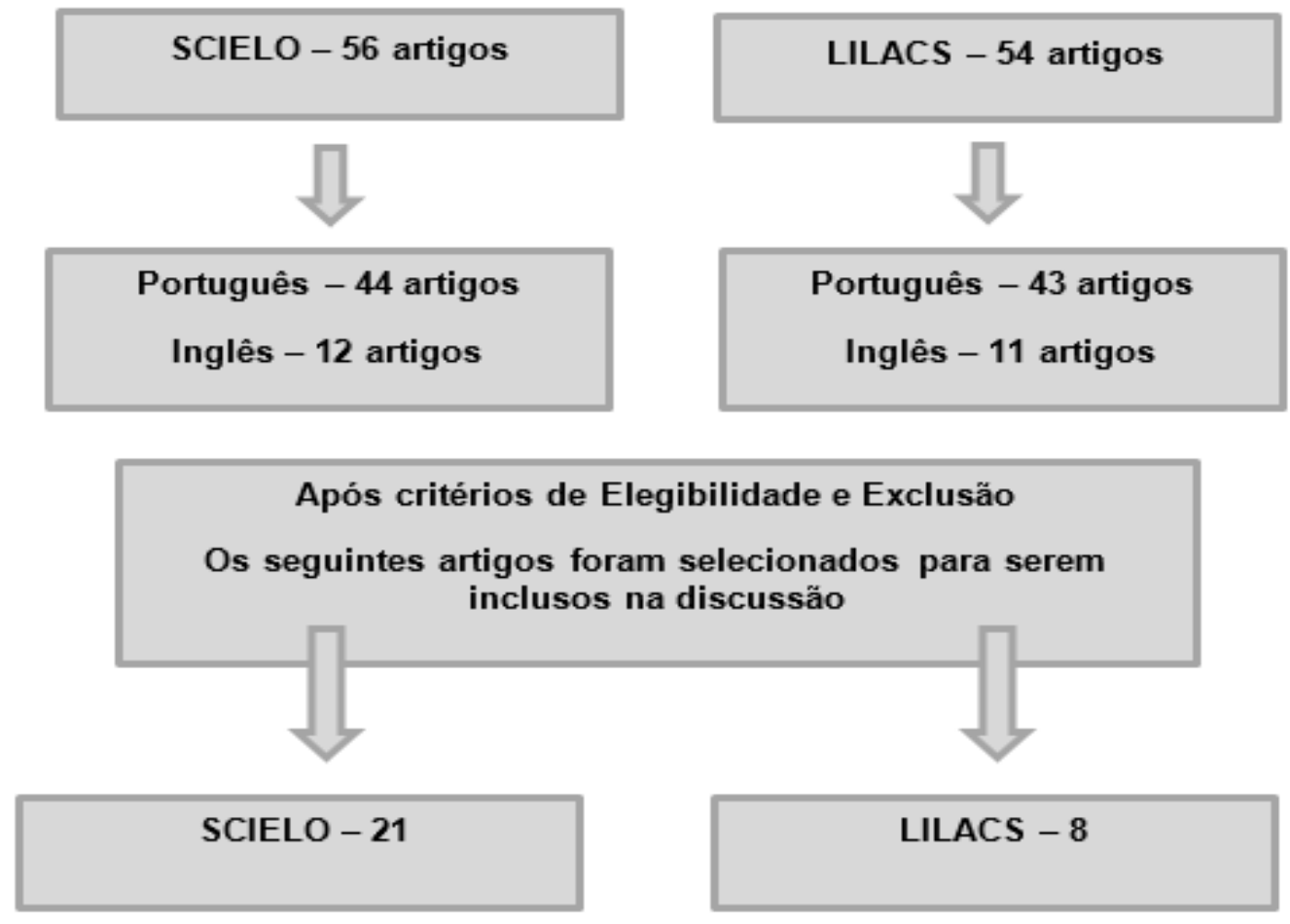

Fonte: Amazonas MAM, et al., 2020.

De acordo com Knihs NS, et al. (2015) o baixo índice de doadores é uma problemática que afeta o mundo todo, tanto países desenvolvidos como subdesenvolvidos. Mesmo com os avanços tecnológicos e com as melhorias realizadas no desenvolvimento das atividades para doação ao longo dos anos, ainda se observa que há falhas no processo. Sendo assim, explorar os fatores que dificultam a efetivação de futuros doadores são benéficos.

A Lei no 9.434, de 1997 de 4 de fevereiro determina a juridicidade a respeito da amputação de órgãos de partes do corpo humano a fins de transferência e tratamento, cujo seja o desejo do indivíduo em consentir ou em casos de óbito, cabe a parentela de primeiro grau decidir (BRASIL, 1997).

Esclarecer algumas questões norteadoras sobre o processo para extração de órgãos se faz de suma importância. Deixar claro para a população que para ser um doador efetivo após a morte não é necessário 
que deixe documento com assinatura, apenas diga verbalmente aos familiares sobre sua vontade de querer doar. Por isso, a importância de gerar diálogos sobre o tema na sociedade (SANDRI JVA e KUSE EA, 2019).

De acordo com Pompeu $\mathrm{MH}$, et al. (2014) a ação de transferir os tecidos é um recurso terapêutico que desperta dúvidas, e a falta de compreensão resulta em questionamentos, pela complicação acerca do assunto se tem um desinteresse da sociedade em doar. Logo, sem doações de órgãos não se tem transplantes.

Correia WLB, et al. (2018) abordaram que o sexo masculino é predominante entre os doadores para a ablação de tecidos, do que o sexo feminino. Em seu estudo foi detectado que de pessoas que morrem por morte encefálica, $65,6 \%$ era do sexo masculino. Isso está relacionado ao estilo de vida, o homem está mais propenso a se envolver em acidentes, praticar esportes radicais, beber em excesso, ser violento, entre outros fatores. Em relação à idade, foi observado que a faixa etária de 20 a 39 anos teve um índice maior. Seguido da faixa etária de 41 a 59 anos.

Segundo Bertasi RAO, et al. (2019) em sua pesquisa sobre perfil dos potenciais doadores constataram que após comprovado a condição de morte cerebral, o seguinte passo é autorização da família em permitir a doação de órgãos do falecido. Porém, foi observado que negativa da parentela ainda é crescente e maior causa para não efetivação de transplante e doação. Desta forma, se sanar as causas que levam a recusa familiar, possibilitariamos um aumento nos números de doação.

Corroborando Costa IF, et al. (2017) alegam que o contexto religioso, a carência no entendimento sobre a falência do tecido cerebral juntamente com despreparo dos profissionais na comunicação com os familiares favorecem as chances da família se recusar em autorizar a doação. É importante evidenciar que um número alto dos possíveis colaboradores veio a óbito resultante de falência cerebral. Neste cenário, a má compreensão do diagnóstico por parte da família gera um medo, incerteza e desconfiança, desconfiam que os profissionais possam estar acelerando a morte do ente querido. Acarretando para eles o medo em relação ao tráfico de órgãos, informação essa que é adquirida através dos meios de comunicação e assim, possibilitando à incerteza em relação à permissão a ablação dos tecidos do indivíduo (ROSÁRIO EN, et al., 2013).

Uma das grandes dúvidas que envolvem os familiares frente ao diagnóstico de morte encefálica, é o fato de ver que o coração ainda está pulsando, que o ente querido ainda dê sinais de vida, mesmo que mecanicamente. $E$ isso faz com que os familiares tenham certa resistência e dificuldade em aceitar o diagnóstico (PERREIRA KGB, et al., 2020). A escassez na informação a parentela sobre o que está havendo com o cliente, juntamente com o desconhecimento sobre falência cerebral corrobora com suposições errôneas a respeito das atividades para a extração dos tecidos e órgãos.

Questões como se isso é certo, como o corpo será devolvido e como deixarão o corpo fisicamente após a doação, que são levantadas pelos familiares quando não há informações. O que gera um desconforto e dúvidas sobre autorizar ou não doar (ROZA BA, et al., 2010). Os familiares destacam o tempo de espera para que seja liberado o corpo após a ablação de tecidos, e isso gera uma situação de angústia e estresse para os familiares. O momento de maior estresse relatado pelos familiares é quando ocorre o atraso na liberação, pois isso gera uma pressão por parte dos outros familiares na pressa em quererem velar seu ente querido (CINQUE VM e BIANCHI ERF, 2010).

Crespo M, et al. (2017) enfatizam que é importante lembrar que para os familiares, receber a notícia de que seu ente querido morreu é um momento delicado e paralisante, que deve ser respeito pelo profissional de saúde. Decidir sobre permitir ou se negar a consentir com a amputação dos órgãos é uma decisão que traz consigo um importante questionamento sobre o falecido e tudo que cerca o desenvolvimento das atividades da excisão. Luto, o medo, a saudade e ter que se conformar com a morte é um processo que a familiar terá que passar antes de tomar a decisão.

Rosário EN, et al. (2013) afirmam que a recusa familiar também está relacionada a discordância entre a parentela, onde uma fração da parentela revela o desejo em consentir, a partir do dado momento em que a enfermeira da equipe multiprofissional, explana sobre o processamento em doar, os outros parentelas ficam 
impactados com o assunto e nega-se a ablação de partes do familiar. Desta forma, é dificultada a efetivação da doação.

Silva VS, et al. (2020) destacam que a ablação de tecidos é vista como um gesto solidário pela sociedade. No entanto, esse gesto em permitir a retirada, é feita pela família em um dado momento de perda, luto e angústia. Sendo assim, o apoio, o envolvimento de todos os familiares, pode gerar certo conforto na hora de autorizar a doação, e assim, a família idealiza um sentimento de que o ente querido mesmo após a morte está salvando outras vidas.

Araújo MN e Massarollo MCKB (2014) relatam que a crença religiosa é uma das interferências percebidas pela enfermagem no andamento de ablação de tecidos e órgãos. Para muitas pessoas a fé auxilia nas tomadas de decisões, no entanto, para as religiões as mortes possuem conceitos diversificados. Algumas crenças orientam que o corpo é sagrado, diante disso precisa ser resguardado após o óbito. Sendo assim, isso se torna um fator negativo para permissão da parentela para ablação de tecidos.

A religião é um dos fatores da recusa familiar, pois a família deposita sua fé na esperança de sobrevida do ente querido. É difícil para família aceitar a morte quando se há batimentos cardíacos, mesmo que haja somente por aparelhos e sentir o corpo ainda quente do familiar (PESSOA JLE, et al., 2013).

Sendo uma das principais causas da recusa familiar em permitir a remoção de partes do corpo, o desconhecimento do conceito morte encefálico, ora pela população, ora pelo profissional da saúde. Isso faz com que haja um aumento significativo na fila de espera. Propor uma educação continuada para população seria de suma importância para gerar na sociedade discussões referente à remoção de tecidos e órgãos. (FREIRE ILS, et al., 2015).

Por ser uma condição determinante no processamento de ablação de tecidos, em seu estudo, observou que a maioria dos familiares que não autorizaram a doação alegou que não tinham ciência do anseio do indivíduo em doar após seu falecimento. E quando perguntado a alguns jovens sobre o assunto, a maioria alegou que não autorizam por não terem conhecimento sobre o tema (DALBEM GG e CAREGNATO RCA, 2010).

De acordo com Bonetti CE, et al. (2017) as maiores causas que induzem a recusa familiar estão sujeitas a alterações no decorrer do prosseguimento da remoção de órgãos como, a religiosidade, o desacordo da parentela e o relacionamento da família com a equipe. Todos são fatores que podem ser alterados assim que identificados e esclarecidos. Porém, um dos fatores estudados tem certa resistência, que é o desejo expresso do falecido, quando ainda em vida, em não querer ser doador. Uma adequada abordagem sobre transplantes e doação de órgãos é um ponto fundamental para uma crescente nos números de doadores. As Intensificações de campanhas nas mídias sociais sobre transferir e doar os órgãos pode fazer com que a sociedade consiga expressar sua vontade de querer ser doadora para sua parentela e amigos (PESSOA JLE, et al., 2013).

Para Dalbem GG e Caregnato RCA (2010) mesmo que a extração dos tecidos precisarem ser, exclusivamente, da permissão do familiar, é visto que há uma necessidade em abordar com frequência sobre o assunto, em campanhas informativas, gerar na comunidade debates sobre o assunto. Esse avanço nas ações educativas aumentariam os números de doações, amenizando o tempo de espera de pessoas nas filas para transplante e salvaria muitas vidas.

É de suma importância às ações educativas serem periódicas. Pois as ações incentivam as pessoas a expressarem seu desejo de doar aos familiares em vida, descartando assim uma possível recusa familiar frente ao processo de doação (SANDRI JVA e KUSE EA, 2019). A equipe de enfermagem tem uma grande responsabilidade por ser uma situação muito desafiadora na questão ética do profissional. A parentela sofre ao ouvir a notícia do falecimento do seu parente, desta forma a equipe multiprofissional precisa abraçar os familiares e elaborar estratégias para auxiliar os familiares na ação de consentir ou negar a doação de partes do indivíduo (PESTANA AL, et al., 2013).

O corpo de enfermagem carece compreender que uma das várias partes necessárias, no processamento para ablação de tecidos é o diálogo com a parentela. Logo, se requer um treinamento específico na equipe. 
Também se faz necessário compreender que a entrevista precisa ser realizada, preferencialmente, somente com os familiares de primeiro grau do falecido, pois dessa forma reduz a probabilidade de conflitos entre os próprios familiares na tomada de uma decisão importante (COSTA IF, et al., 2019).

Moraes EL, et al. (2015) afirmam que é essencial que esses profissionais recebam uma capacitação específica em comunicação, pois diariamente prestam assistência a pacientes que podem evoluir para morte cerebral. Foi observado durante o seu estudo que enfermeiros que ofertavam uma comunicação humanizada com os familiares do falecido no processo de remoção geraram um relacionamento afetuoso, o que produzia chances para se obter concordância para doação de órgãos.

Knihs NS, et al. (2019), afirma que a educação permanente é uma importante ferramenta utilizada pelo profissional que trabalha, afim de alcançar a permissão dos familiares na extração de tecidos, pois as táticas desenvolvidas podem alavancar para o aperfeiçoamento no conhecimento científico, união entre a equipe, aprimoramento e qualidade nas atividades executadas, crescimento na arrumação das atividades fornecidas junto com uma assistência que abrangem as necessidades dos familiares e do ente querido, ocasionando assim maior expectativa na efetivação de retirada de órgãos.

A equipe de enfermagem está presente na etapa de decisão familiar, oferecendo apoio, acolhimento e uma ausculta sensível à família. Explicando para eles que houve um dano irreversível no cérebro do indivíduo (RIBEIRO KRA, et al., 2020). Segundo Cavalcante LP, et al. (2014) a equipe de enfermagem é a classe profissional que tem uma relação maior com a família do paciente, desde a entrada do paciente até o recebimento da notícia de que o paciente veio a óbito. E por ter essa relação mais próxima dos parentes do falecido, a competência do enfermeiro vai além de somente informar, mas abrange o acolhimento dos familiares, e assim, oferecendo aos mesmos uma ausculta sensível.

Após a notificação da família sobre a morte do familiar, o enfermeiro observa que os familiares apresentam dificuldades em consentir sobre a ablação, isso é pelo pouco tempo que tiveram em aceitar o falecimento do ente querido até o momento da decisão. Os familiares têm ciência da relevância da ablação dos tecidos e os benefícios que a mesma trás, no entanto, por não conseguirem aceitar a morte do familiar, autorizar a doação iria cooperar com a morte do familiar (CAJADO MCV e FRANCO ALS, 2016).

O emocional é uma condição que pode induzir a decisão da família na hora de autorizar a captação de órgãos. As famílias que não se sentiram acolhidos devidamente pela equipe, desde a entrada do paciente até o momento da triste notícia, estão mais dispostos a não autorizar. Outra questão observada foi à demora da liberação do corpo, o procedimento realizado depois da conscientização para ablação dos órgãos é algo demorado, e isso gera na família uma angústia maior e assim, tendo-se a uma negação na decisão da família (BARRETO BS, et al., 2017). Santos MJ e Massarollo MCKB (2011) declaram que um ponto importante visto pelos profissionais é a questão do ambiente que é realizado a entrevista com a família, cuja muita das vezes é praticada na beira do leito do falecido. $E$ isso é visto como algo negativamente pelo profissional. $O$ ambiente tranquilo e propicio para se realizar uma conversa proveitosa com a parentela do potencial concessor, isto proporcionaria no processo e aumentaria as chances de a família autorizar a doação.

\section{CONSIDERAÇÕES FINAIS}

Em âmbito social, é crucial a elaboração de campanhas educativas periódicas que incentivem o diálogo entre as pessoas, sanando a desinformação dos parentes sobre a vontade do indivíduo em querer ser ou não um possível doador em decorrência de óbito. No espaço hospitalar, é imprescindível que a enfermagem preste assistência a pacientes que possam evoluir para o quadro de morte cerebral, desta forma, é relevante investir na capacitação da equipe para que venha ser ofertada a assistência necessária ao potencial doador e sua família. Para o enfermeiro o consentimento da retirada de órgãos e tecidos se inicia desde a assistência aos familiares, ofertando conhecimento, gerando a assimilação dos mesmos sobre a falência cerebral, cooperando para um relacionamento com a parentela, estando presente na resolução de dúvidas acerca do ato de doar, no enfrentamento de conflitos emocionais, na permissão da doação ou respeitando a negativa da parentela. 


\section{REFERÊNCIAS}

1. ARAUJO MN, MASSAROLLO MCKB. Conflitos éticos vivenciados por enfermeiros no processo de doação de órgãos. Acta paul. enferm., 2014; 215-220.

2. BARRETO BS, et al. Fatores relacionados à não doação de órgãos de potenciais doadores no estado de Sergipe, Brasil. Revista Brasileira de Pesquisa em Saúde/Brazilian Journal of Health Research, 2017; 18(3): 40-48.

3. BERTASI RAO, et al. Perfil dos potenciais doadores de órgãos e fatores relacionados à doação e a não doação de órgãos de uma Organização de Procura de Órgãos. Rev. Col. Bras. Cir., 2019; 46(3): e20192180.

4. BONETTI CE, et al. Doação de órgãos e tecidos e motivos da sua não realização. Revista de Enfermagem UFPE on line , 2017; 3533-3541.

5. BRASIL Lei de no 9.434, de 4 de fevereiro de 1997.In: Planalto. Disponível: http://www.planalto.gov.br/ccivil_03/leis//9434.htm. Acesso em: 20 de set 2020.

6. CAJADO MCV, FRANCO ALS. Doação de órgãos e tecidos para transplantes: impasses subjetivos diante da decisão familiar. Rev. baiana saúde pública, 2016; 40(2).

7. CAVALCANTE LP, et al. Cuidados de enfermagem ao paciente em morte encefálica e potencial doador de órgãos. Acta paul. enferm., 2014; 567-572.

8. CINQUE VM, BIANCHI ERF. Estressores vivenciados pelos familiares no processo de doação de órgãos e tecidos para transplante. Rev. esc. Enferm., 2010; 44(4): 996-1002.

9. CORREIA WLB, et al. Potencial doador cadáver: causas da não doação de órgãos. Enfermagem em Foco, 2018;

10. COSTA AM, et al. Abordagem da família na doação de órgãos: percepção de enfermeiras. Revista de Enfermagem UFPE on line, 2010; 13(5): 1253-1263.

11. COSTA IF, et al. Fragilidades na atenção ao potencial doador de órgãos: percepção de enfermeiros. Rev. Bioét., 2017; 25(1): 130-137.

12. DALBEM GG, CAREGNATO RCA. Doação de órgãos e tecidos para transplante: recusa das famílias. Texto contexto - enferm., 2010; 19(4): 728-735.

13. FREIRE ILS, et al. Estrutura, processo e resultado da doação de órgãos e tecidos para transplante. Rev. Bras. Enferm., 2015; 68(5): 837-845.

14. KNIHS NS, et al. Aplicação de instrumentos de qualidade em doação de órgãos e transplantes da Espanha validados em hospitais pilotos em Santa Catarina. J. Bras. Nefrol., 2015; 37(3): 323-332.

15. LILLO-CRESPO M, et al. Aproximación fenomenológica al significado e impacto de la donación de órganos en la familia. Aquichan, 2017; 17(1): 18-29.

16. MORAES EL, et al. Experiências e expectativas de enfermeiros no cuidado ao doador de órgãos e à sua família. Rev. esc. enferm. USP, 2015; 49(spe2): 129-135.

17. MORAIS TR, MORAIS MR. Doação de órgãos: é preciso educar para avançar. Saúde debate, 2012; 36(95): 633-639.

18. PASSONI R, et al. Elementos clínicos y epidemiológicos de entrevistas familiares para la donación de órganos y tejidos. Enferm. glob., 2017; 16(46): 120-153.

19. PEREIRA KGB, et al. Doação de órgãos em serviço hospitalar: principais motivos à negativa na autorização. Rev. Enferm. UFSM, 2020; 10(e4): 1-14.

20. PESSOA JLE, et al. Avaliação das causas de recusa familiar a doação de órgãos e tecidos. Acta paul. enferm., 2013; 26(4): 323-330.

21. PESTANA AL, et al. Pensamento Lean e cuidado do paciente em morte encefálica no processo de doação de órgãos. Rev. esc. enferm. USP, 2013; 47(1): 258-264.

22. POMPEU MH, et al. Fatores negativa na negativa da doação de tecido ósseo. Acta paul. enferm., 2014; 27(4): 380384.

23. QUINTANA AM, ARPINI DM. Doação de órgãos: possíveis elementos de resistência e aceitação. Bol. Psicol., 2009; 59(130): 91-102.

24. RIBEIRO KRA, et al. Morte encefálica e o processo de doação de órgãos: uma atenção ao familiar. Rev. Pesquisa, 2020; 12: 189-195.

25. ROSARIO EN, et al. Recusa familiar diante de um potencial doador de órgãos. Cad. saúde colet., 2013; 21(3): 260266.

26. ROZA BA, et al. Doação de órgãos e tecidos: relação com o corpo em nossa sociedade. Acta paul. enferm., 2010; 23(3): 417-422.

27. SANDRI JVA, KUSE EA. O significado do sim para a família no processo de doação de órgãos. Rev. Nursing, 2019; 22(254): 3047-3051.

28. SANTOS MJ, et al. Entrevista familiar no processo de doação de órgãos e tecidos para transplante. Acta paul. enferm., 2012; 25(5): 788-794.

29. SILVA VS, et al. A efetividade do processo de doação de órgãos frente a nova legislação. Nursing (Säo Paulo), 2020; 23(264): 4018-4026. 